\title{
IV JORNADAS DO QUATERNÁRIO MUDANÇAS AMBIENTAIS E IMPACTOS HUMANOS NA FACHADA ATLÂNTICA OCIDENTAL
}

ANDRÉ TORRES ${ }^{1}$

MigUEL GERALDES ${ }^{2}$

Nos dias 9 e 10 de Dezembro de 2011 decorreram em Coimbra as IV Jornadas do Quaternário, promovidas pela Associação Portuguesa para o Estudo do Quaternário (APEQ). Foram organizadas quatro sessões (duas por dia), cada uma iniciada com uma conferência, seguida de comunicações temáticas. As Mudanças Ambientais e Impactos Humanos na Fachada Atlântica Ocidental foram o tema central.

Nesta síntese, adopta-se uma abordagem temática, em vez da sequência cronológica das sessões, as quais foram organizadas em três blocos temáticos gerais: i) proxies de evolução climática e reconstrução paleoambiental; ii) palinologia e paleoecologia; iii) o papel da investigação paleoambiental (geoarqueológica) no decifrar dos impactos antrópicos no Plistocénico tardio e Holocénico. Além das conferências destacamos algumas sessões.

\section{PROXIES DE EVOLUÇÃO CLIMÁTICA E RECONSTRUÇÃO DE PALEOAMBIENTES}

Na palestra de abertura, intitulada Marine Reservoir Effects: problems and prospects for radiocarbon dating, Phillipa Ascough, do Scottish Universities Environmental Research Centre (SUERC), Universidade de Glasgow, abordou o impacto do Efeito de Reservatório Marinho (MRE) nas cronologias da fachada Atlântica. Segundo a investigadora, embora as datações de radiocarbono $\left({ }^{14} \mathrm{C}\right)$ sejam essenciais nas pesquisas paleoambientais e arqueológicas, possibilitando a correlação de dados recolhidos em diversos pontos do globo, é necessário ter em conta que, devido a variações no clima e na circulação oceânica, o MRE varia com a localização geográfica e existem diferenças fundamentais entre as idades de ${ }^{14} \mathrm{C}$ de amostras terrestres e

1 Bolseiro de Doutoramento FCT e Investigador do CEG-IGOT-UL, Núcleo SLIF - Sistemas Litorais e Fluviais: Dinâmicas, Mudanças Ambientais e Ordenamento do Território. E-mail: andre.rocha.torres@gmail.com

2 Bolseiro de Doutoramento da FCT e Investigador do CEG-IGOT-UL, Núcleo de Investigação CliMA - Clima e Mudanças Ambientais. E-mail: mgeraldes@campus.ul.pt 
marinhas para o mesmo momento, podendo as últimas apresentar idades mais antigas. A investigação desenvolvida, nos últimos anos, por Ascough vai no sentido de quantificar o MRE em diversos pontos da fachada Atlântica (Escócia, Irlanda, Islândia e Ilhas Faroe), particularmente para o Holocénico médio e tardio, de modo a poder calibrar amostras que contenham carbono marinho e construir cronologias ambientais e arqueológicas para os casos de estudo, em que os dados locais recolhidos são comparados usando cronologias absolutas.

Por sua vez, Aaron Potito, da National University of Ireland, Galway, apresentou o tema Reconstructing the past to inform the present: Palaeoenvironmental perspectives on environmental change, que se centrou na reconstrução paleoambiental multi-proxy aplicada a sedimentos lacustres. O autor apresentou resultados de diversos estudos limnológicos e dendrocronológicos, efectuados em diferentes pontos do globo, nomeadamente na Irlanda (Lough Beg), China (Ertan) e América do Norte (Sierra Nevada), com uma abordagem baseada na construção de um training set, que envolve a recolha de Chironomidae (família de moscas não-mordedoras da ordem dos dípteros) da superfície e dos sedimentos lacustres. Esta análise permitiu determinar as variáveis ambientais dominantes e desenvolver funções de transferência aplicáveis a toda a coluna vertical das sondagens. Os resultados obtidos pela análise de Chironomidae deverão ser confrontados com os derivados da dendrocronologia, palinologia, paleolimnologia e geoquímica dos sedimentos lacustres, de forma a encontrar padrões de mudança ambiental e avaliar os impactos do aquecimento global no Plistocénico tardio e Holocénico, para diferentes escalas espaço-temporais.

A última palestra deste bloco temático, intitulada The influence of climatic conditions on vegetated aeolian dune landscape evolution, foi apresentada por Joanna Nield, da Universidade de Southampton. Nesta sessão, foi exposto um modelo de autómatos celulares (DECAL, Discrete Ecogeomorphic Aeolian Landscape model) para a formação e evolução de dunas do tipo parabólico e nebkha, tomando em conta os processos geomórficos associados e o desenvolvimento da vegetação dunar, como resposta a alterações climáticas e outras perturbações induzidas no sistema. Quando é aplicada uma resolução celular mais elevada ao modelo, a vegetação assume um papel fundamental, dado que diferentes cenários de desenvolvimento da vegetação dunar podem originar diferentes caminhos evolutivos. Nield salientou a relação intrínseca entre as componentes ecológicas e os processos geomorfológicos abióticos do sistema, com a morfologia e escala dos complexos dunares a serem controlados pela vegetação, numa grande complexidade de trajectórias de desenvolvimento e estados de equilíbrio da paisagem.

Das diversas comunicações orais deste tema, destacam-se quatro que, de certa forma, estão subordinadas à temática das proxies de evolução climática e reconstrução de ambientes do Plistocénico e Holocénico. Elas vão ser sintetizadas de acordo com a ordem de apresentação.

A comunicação de Monge Soares, Radiocarbon dating of aeolianite formation, consistiu na apresentação de uma geocronologia relativa, resultante da datação de depósitos eólicos carbonatados consolidados (eolianitos) da costa ocidental de Portugal (Praia Azul, S. Julião, Samarra, Magoito, Aguda, Praia das Maçãs e Oitavos). O autor mostrou que a datação por radiocarbono de eolianitos pode ser usada como ferramenta para definir a contemporaneidade dos depósitos e estabelecer cronologias relativas regionais para depósitos arenosos carbonatados.

A comunicação de Pedro Proença e Cunha, Geomorphological and sedimentological characterisation of the Mondego River terraces at Maiorca-Vila Verde (western central Portugal), incidiu no estudo geomorfológico e sedimentológico dos terraços fluviais da área de Maiorca-Vila Verde. Através de datações de luminescência óptica estimulada (Optically Stimulated Luminescence, OSL) foi possível datar os terraços (o terraço mais antigo detém uma idade mínima de 120 ka, MIS 5) e estabelecer uma cronologia de fases de incisão fluvial e episódios sucessivos de entalhe fluvial alternados com equilíbrio dinâmico, seguidos, em 
muitos casos, por agradação do sistema. Segundo este autor, a glacio-eustasia foi o factor principal de controlo fluvial nos processos descritos.

Luca Dimuccio, na comunicação Late Pleistocene millenial-scale paleoclimatic fluctuations from the continental record of the Sicó massif and Outil/Cantanhede plateau (central-western Portugal), apresentou resultados do estudo desenvolvido em sequências sedimentares de contextos cársicos e fluvio-cársicos (Maciço do Sicó e planalto de Outil/Cantanhede). A investigação permitiu aferir períodos de agradação e fases de erosão/estabilização durante o Plistocénico tardio (MIS 3 e 2), assim como estabelecer uma correlação dos depósitos continentais com o registo marinho. As inconformidades sedimentares continentais foram associadas a flutuações paleoclimáticas, com a quantidade de precipitação a ser o factor forçador determinante e tendo sido identificado o sinal de eventos Heinrich nos depósitos estudados.

SW Iberia sea-level rise curve and antropogenic activities inferred from the postglacial sedimentary infill of the Guadiana river foi o título da comunicação proferida por Tomasz Boski, na qual o autor propõe uma curva de subida do nível médio do mar que abrange os últimos 13,5 ka para margem Atlântica do sudoeste da Península Ibérica. Esta reconstrução, desenvolvida com base nos depósitos sedimentares de colmatação do estuário do Rio Guadiana, permitiu, também, estabelecer uma cronologia dos eventos que influenciaram a colmatação sedimentar do estuário no período pós-glaciário. Boski conseguiu também separar os contaminantes geoquímicos naturais dos de natureza antropogénica, assim como constatar a utilidade do estudo de sequências sedimentares pós-glaciares para reconstruir as mudanças históricas nas componentes da água regional.

\section{PALINOLOGIA E PALEOECOLOGIA}

No segundo dia, António Martínez Cortizas, da Universidade de Santiago de Compostela, apresentou a conferência The role of palaeoenvironmental research in deciphering Holocene human impacts. Para o autor, o uso de multiproxies paleoambientais é uma das poucas ferramentas disponíveis para avaliar, não só a complexa evolução dos ecossistemas continentais passados, mas também o grau de alteração antropogénica dos ciclos biogeoquímicos "naturais". Martínez Cortizas trouxe alguns exemplos do Noroeste ibérico, onde foi feita a reconstrução da poluição atmosférica por metais, devida à mineração e metalurgia, desde há 8000 anos, estabelecendo relação com as mudanças no coberto florestal e degradação dos solos (erosão, acidificação e ressedimentação). Feita a comparação entre os registos de diferentes metais pesados e os registos geoquímicos e palinológicos no mesmo arquivo de turfa, foi possível isolar as fases de contaminação polimetálica (como o período romano ou a Revolução Industrial) e distingui-las dos períodos em que apenas um ou alguns metais dominaram (como, por exemplo, Ni na Idade do Bronze). Conclui que existe sincronização entre os picos de poluição e o destino das florestas: o coberto florestal diminui quando a poluição aumenta.

Várias foram as comunicações apresentadas neste bloco. Referir-se-ão as de Luis Gómez-Orellana, Pablo Ramil Rego e Castor Muñoz Sobrino. Na primeira, The landscapes of the $M I S-3$ in the lowlands close to the sea of NW Iberia, foram discutidas as mudanças na paisagem, reconstituída a partir de perfis de pólen de vários locais do Noroeste ibérico durante o interestadial MIS $3^{i}$ da última glaciação. Os dados palinológicos revelaram que houve, pelo menos, três fases de expansão de pólen de árvores de folha caduca da Cantábria à Galiza (géneros Fagus, Quercus e Betula), intercaladas por outras fases, onde o pólen de Ericaceae e Gra- 
mineae dominou, com algum Pinus. Os mesmos autores referiram, na comunicação Refuges for temperate deciduous trees in the littoral area from NW Iberia during the last glacial period, que os modelos, utilizados para explicar a recolonização holocénica da Europa Central e do Norte, estão alicerçados na aceitação de que todas as áreas de refúgio para a flora mesófila e termófila se situavam nas áreas costeiras mais meridionais da Europa. Quando a expansão florestal pós-glaciária recomeça, essas regiões funcionam como focos de difusão, identificados nas penínsulas Balcânica, Apenina e Ibérica. Contudo, há resultados nos territórios Cantabro-atlânticos que questionam esse postulado. As análises polínicas recentes de alta resolução demonstram que as regiões costeiras da Cantábria, tradicionalmente vistas como estando fora dos refúgios meridionais clássicos, terão servido de ponto de partida para muitas destas árvores durante as recolonizações quaternárias. Também aqui terá existido um refúgio glaciário. Particularmente, o extremo mais ocidental da Cantábria é uma área de excelentes possibilidades de refúgio potencial, onde a dinâmica pós-glaciária ainda não é bem conhecida de acordo com a comunicação, do mesmo grupo de autores, intitulada Environmental changes in the westernmost extreme of the Cantabrian range during the postglacial period. Neste sentido, a comparação entre pólen e dados de outras variáveis das terras altas asturianas, leonesas, galegas e minhotas, pode contribuir para decifrar as principais alterações ambientais que afectaram o Noroeste da Península, e, particularmente, o extremo ocidental da Cordilheira cantábrica. O facto de se tratar de uma área de transição entre os climas Atlântico e Mediterrânico, com influência continental no interior, aliado a um relevo muito elevado e acidentado, introduz uma série de variantes locais, torna esta região especialmente interessante para reconstruções paleoambientais.

Ainda com base na palinologia, Randi Danielsen, na comunicação intitulada The central portuguese littoral - 5000 years of change, traçou as fases de actividade eólica, formação de campos dunares, evolução da linha de costa e flutuações do nível do mar, numa secção do litoral centro de Portugal (Quiaios), durante os últimos 5000 anos. O impacto da acção antrópica foi considerado, pela palinóloga, o principal factor de mudança ambiental na área estudada, para o intervalo temporal estipulado.

Sandra Gomes e colaboradores, apresentaram a comunicação $A$ análise polínica do Poço do Pinheirinho: um registo interglacial ou interestadial na costa alentejana?. Esta análise, feita após sondagens nas depressões interdunares do Poço do Pinheirinho e nos Poços do Barbaroxo (litoral alentejano) permitiu identificar, num período desde há 43870 cal BP, uma primeira fase, de carácter mais quente e seco (com presença de Pinus sp., Quercus suber, Anthemis sp.), uma fase intermédia de características mais húmidas (picos de Alnus sp., Salix sp.e presença de Osmunda sp.) e uma fase final, de maior aridez (Artemisia sp., Cistus sp, Cyperaceae).

Também sobre um ambiente lacustre costeiro, falaram Helena Ribeiro e colaboradores. No trabalho Study of a Middle Holocene organic-rich deposit from Castelo do Neiva (Portugal), caracteriza-se um depósito orgânico (datado de $5880 \pm 60$ 14Cyr BP), encontrado na actual praia de Castelo do Neiva (Viana do Castelo). Os resultados revelaram a existência de um ambiente do princípio do Holocénico com matéria orgânica num estádio inicial da evolução, compatível com uma fase formação (?) de turfa. As plantas lenhosas e hidrófitas ocupavam a área da praia actual; a ausência de pirite sugere a existência de um pântano florestal, onde o nível de água estava acima da superfície topográfica do pântano.

Delminda S. Moura e colaboradores apresentaram Nivel médio relativo do mar vs. linha de costa, trabalho inserido no projecto europeu COST Action TD0902- SPLASHCOS. Sugerem o estudo as células litorais locais, propícias à reconstituição da evolução da linha de costa, tal como acontece na Baía de Armação de Pêra, onde dunas e rochas de praia geradas entre os 9 e os $2 \mathrm{ka}^{\mathrm{ii}}$ se encontram preservadas. O objectivo é verificar, se no máximo trans- 
gressivo aos 6000 cal BP, houve desvios nas curvas de variação do nível médio do mar ao longo do Holocénico, os quais são cada vez mais divergentes entre locais com importantes desvios ao sinal eustático.

\section{INVESTIGAÇÃO PALEOAMBIENTAL E IMPACTOS ANTRÓPICOS NO PLEISTOCÉNICO TARDIO E HOLOCÉNICO}

Destacamos algumas comunicações no terceiro tema, que melhor espelham a investigação em curso. Sérgio Monteiro-Rodrigues em Novos elementos para o estudo da ocupação humana plistocénica no litoral de V. Nova de Gaia, Norte de Portugal, referiu-se à cronologia de mais de uma centena de artefactos macrolíticos, conectáveis com o Paleolítico Inferior (bifaces, machados, núcleos, utensílios sobre lasca, entre outros), na estação paleolítica da Praia da Aguda (Arcozelo, Gaia). Com base na tipologia da indústria lítica, o autor põe em causa a correlação com um depósito marinho, a que é atribuída uma idade eemiana.

No trabalho de Mariana Diniz e Pablo Árias, Os inícios do Atlântico no Baixo Vale do Sado (Portugal): problemáticas em torno da ocupação dos concheiros foi também tratado o caso do Sado. A instalação de comunidades mesolíticas, ao longo das duas margens do troço vestibular do Sado, entre a Barrosinha e a barragem de Vale do Gaio, terá ocorrido a partir de 7300 BP (Óptimo Climático Atlântico), em função das datas de ${ }^{14} \mathrm{C}$ hoje disponíveis. Ao invés do modelo tradicional, que integra todo o Sul de Portugal, durante o Mesolítico final, num horizonte cultural próprio da Europa atlântica, os concheiros do Sado parecem distinguir-se dos concheiros do Tejo (Muge), tendo em conta as análises espaciais, estratigráficas, faunísticas e isotópicas. A afinidade do Sado com os povoados mediterrâneos parece ser grande, enquanto que os Concheiros de Muge se assemelham aos atlânticos.

A comunicação Holocene fire and vegetation interactions in the Serra da Estrela (Portugal), de João Araújo e Simon Connor versou sobre uma nova análise microscópica do carvão fossilizado presente nas amostras de pólen do Charco da Candieira (Serra da Estrela), que tinham sido extraídas nos anos 80 por Janssen, van der Knaap e van Leeuwen, e que indicam que a história do fogo e do desenvolvimento da vegetação na Serra da Estrela estão estreitamente interligadas. As concentrações de carvão vegetal são elevadas no período 3500-900 cal BP, correspondendo a uma fase de grande desflorestação. Os incêndios parecem ser uma parte importante do funcionamento dos ecossistemas serranos e devem ser considerados na elaboração de futuros planos de gestão de fogo para o Parque Natural da Serra da Estrela.

Em Reconstructing Holocene evolution in the archaeological site of Campo Lameiro (NW Spain): an interdisciplinary approach to geoarchaeology, Manuela Costa-Casais e colaboradores sublinharam o potencial explicativo de depósitos sedimentares para a reconstrução das mudanças ambientais no Holocénico em Campo Lameiro. A ocorrência de várias fases de erosão / sedimentação é coetânea com períodos conhecidos de Holocénico: mudança climática abrupta (evento ka 8.2), o início do Neoglaciação (ca. 6 ka BP) ou o evento 2,8 ka, húmido e frio, assim como outras fases de intensa pressão humana.

No mesmo sentido, M. Assunção Araújo e Manuel João Abrunhosa apresentaram Aspectos geológicos e geomorfológicos da orla costeira de Labruge (Vila do Conde, $\mathrm{NW}$ de Portugal). A conservação de formas fósseis correspondentes a antigos estacionamentos do mar onde, muitas vezes, os respectivos depósitos estão ainda conservados, é um proxy que poderá revelar-se útil em estudos paleogeográficos no Norte de Portugal.

Nuno Inácio e colaboradores apresentaram Impacto ambiental da primeira mineração e da metalurgia especializada no Sudoeste da Península Ibérica, divulgando os resultados preliminares de estudo palinológico e geoquímico (sedimentos) e de bioindicadores 
como a ameijoa-boa (Tapes decussata), centrado na Província de Huelva e no Algarve oriental (aqui como consequência da mineração na Faixa Piritosa Ibérica, onde floresceu uma economia mineira e metalúrgica tecnológica e socialmente especializada durante o III Milénio ANE). Os autores evidenciaram não apenas um processo gradual de desflorestação acentuada, mas também uma contaminação ambiental por metais pesados.

Na comunicação Modelo de gestão e circulação de sílex há 5000 BP na faixa litoral entre Nazaré e Peniche (Estremadura Portuguesa), Patrícia Jordão e Nuno Pimentel mostram que, no Calcolítico, se admite que a área inundada entre a Nazaré e Peniche tenha permanecido pouco alterada relativamente ao máximo transgressivo holocénico, constituindo-se uma faixa litoral propícia à circulação de sílex.

Cleia Detry apresentou o estudo zooarqueológico Questões sobre a influência ambiental e humana nos moluscos do Monte Molião (Lagos, Portugal). Nesse sítio arqueológico, ocupado a partir da Idade do Ferro até à Época Romana Imperial (século IV a.C. a II d.C.), foram avaliadas as diferenças entre a dieta no Período Romano Republicano e a do Período Romano Imperial, que parecem indicar alterações: o ambiente estuarino de baixa energia, favorável ao berbigão, parece ter sido perturbado por mudanças de ordem cultural (diferentes preferências no período imperial).

Foram ainda mostrados resultados de um trabalho multidisciplinar entre geologia e geoarqueologia, Evidências geológicas e arqueológicas para a transição climática entre o Período Quente Romano e o "Período das Trevas" no SW alentejano (Portugal), realizado a sul da Lagoa de Santo André, num complexo dunar de idade plistocénica. Em dois dos alinhamentos interdunares desenvolveram-se, nos últimos 7500 anos, turfeiras sub-litorais (Poços do Barbaroxa de Baixo, do Meio, de Cima e Lagoa da Sancha), de enchimento essencialmente orgânico. Nestas depressões efectuaram-se 71 sondagens, que foram objecto de estudo sedimentológico, geoquímico, isotópico $\left({ }^{14} \mathrm{C}\right)$ e paleoecológico (diatomáceas), complementadas com informação polínica. Os resultados revelaram sete períodos de terrestrialização, alternando com períodos de inundação, síncronos em todas as turfeiras. Os eventos de terrestrialização correspondem a épocas de maior aridez e clima mais frio, com redução do espaço límnico e progressão da vegetação marginal para o centro da turfeira. Os eventos pós 2350 cal BP, marcados nas várias sondagens, parecem corresponder a oscilações climáticas. No mesmo sentido apontam escavações arqueológicas da urbs romana de Mirobriga (Chãos Salgados, Santiago do Cacém), a cerca de $15 \mathrm{~km}$ da costa atlântica e da Lagoa de Santo André, ao confirmarem uma deterioração climática em 280 d.C. (= 1670 cal BP). De facto, numa casa urbana (domus) e numa rural (villa), detectou-se o abandono do modelo arquitectónico romano de cariz mediterrânico, com pátio central sem cobertura, aproximadamente no séc. III d.C., ou mais provavelmente início do séc. IV d.C., praticamente contemporânea da alteração climática detectada nos estudos geológicos na costa atlântica. Tal significa que se abandonou o modelo de casa com pátio aberto interior, que passou a ser fechada e com sistema de aquecimento. As datações foram obtidas através das cronologias de fabrico e circulação da cerâmica fina de mesa (terra sigillata), em contexto estratigráfico.

1 O "Marine Isotope Stage" no 3 (ou MIS3) é o período ocorrido entre há 60000 e 27000 anos, durante o último ciclo glaciário, no qual ocorreram diversas fases climáticas quentes, com mudanças abruptas, conhecidas por sua vez por "eventos Dansgård-Oeschger" (ou, simplesmente, eventos DO).

2 A unidade ka quer dizer kiloanos, ou seja, um milhar de anos. 